a guess. We regard the whole as forming an abdominal plate, composed of different pieces, joined by sutures, and which covered the under side of the head and, it may be, part of the body of the Pteraspis. The pieces we possess are numbered in the diagram $1,2,3$, and the

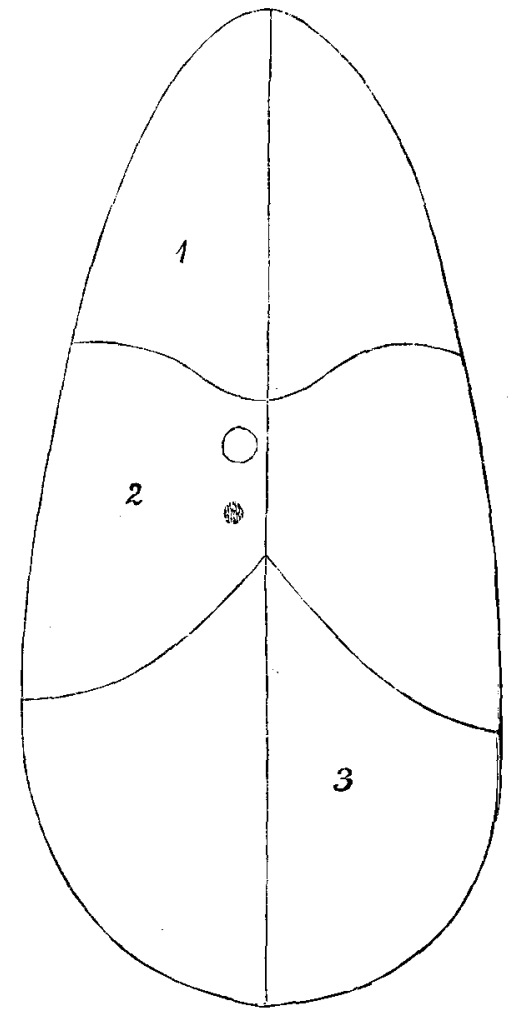

Fig. 3. others have not occurred to us. In 1 we cannot discover any trace of the eye-socket, which, had this been the anterior portion of a dorsal plate, ought to have been displayed; but in 2 there is a round orifice, to which a sucking apparatus might have been well attached. If this interpretation be correct, and be confirmed by further evidence, then, at length, we have reached the method in which the Pteraspis and its kindred Cepbalaspis sought and received their food in the waters. The separate plates seem to be bone, composed like that of the cephalic buckler, and were apparently joined together by deep sutures. The bone covering the upper surface of the head presented a solid mass to any opposing object; but that covering the under surface, as less exposed, was formed of different pieces, and thus flexible wherewithal. And we have observed that Plate 1 covers Plate 2 by a deep marginal socket; so that the plate to which a sucker might be attached could not be torn from its place without the resistance of the other.

\title{
CORRESPONDENCE.
}

\section{Origin of Flint Veins in Chalk.}

DEAR SIR, -A short time since a paper appeared in your publication reviewing the various theories concerning the origin of the chalk flints. No notice was then taken of a theory which, to my mind, explains the origin of flint better than any of those theories which have as yet been 
advanced. Before explaining this theory $I$ will allude to a phenomenon which is apparent in nearly every large exposure of flint-bearing chalk. Seams of flint, often not more than an inch in thichness (sometimes much less), may be seen in the chalk, running at almost right angles to the lines of stratification. From these seams it is possible to detach slabs some feet in superficial area, but only an inch or so in thickness. Now, I ask any person who has the slightest knowledge of the nature of deposition and stratification, whether such a mass as I have described could have been formed at the bottom of the sea round a nucleus of any description, and then have been deposited with the chalk in such a position, viz. at a considerable angle to the lines of stratification. I think that the answer will be in the negative, and that we must have some other theory than that held by Dr. Bowerbank to account for the presence of, at any rate, such masses as these. You have probably noticed the seams, to which I allude, yourself, as they are abundant every where along the south-western coast of England. My attention was first drawn to them in the cliffs between Brighton and Rottingdean, where many and striking examples may be seen. The only theory which can explain these occurrences, and which is sound as far as I can see in other respects, was held, I believe, by the late Professor Henslow, who considered that the chalk flints had been formed after the deposition of the calcareous stratum in which they are found, during its elevation from the sea, by the percolation and concentration of water, highly charged with silica, into cavities left by the decomposition of animal and vegetable matters which had been enclosed. In the process of drying, fissures would naturally form in the chalk, in which the siliceous water could accumulate and leave its deposit of flint, in the same manner as it had accumulated and formed "nodular" masses in the cavities left by the decomposition of sponges, echino-

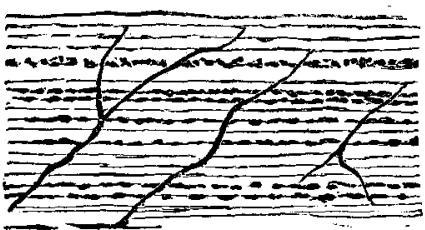
derms, mollusks, etc. I think it is also probable that the gases formed by the decomposition of these organic bodies would enlarge the cavities formed in the yielding chalk; and might not some chemical affinity or exchange also have assisted in the elimination of the siliceous particles from the water?

I should be glad to hear from yourself or correspondents, either facts which will tend to support this theory, or some other hypothesis which will better explain the occurrence of these continuous seams of flint. I enclose you a sketch of the cliff with flint seams, and remain,

September 8th, 1861.

Yours, ete,

Silex.

\section{The Red Sandstone Blocks of Dunmanuay.}

Sir,-The beautiful representation of the Old Red Sandstone block of Dunmanway, county Cork (given at page 248, 'Geologist' for July) gives rise to the following suggestions :-

Dunmanway's Old Red Sandstone blocks stand forth as rocks

Of water-markings; not rubs and jolts of ice-blocks ;

Water went round to mark them. 